\title{
OUTCOME OF CHILDREN WITH RETINOBLASTOMA TREATED WITH PRIMARY CHEMOTHERAPY
}

\section{Tariq Muhammad Saeed', Zafar Iqbal ${ }^{2}$}

\section{ABSTRACT}

OBJECTIVE: To study the outcome of children with retinoblastoma treated with primary chemotherapy.

METHODS: This was a hospital-based cohort prospective study of 9 I children with retinoblastoma out of which 27 children (32 eyes) fulfilled the inclusion criteria. These children were admitted to Ophthalmology Unit, Lady Reading Hospital, Peshawar, Pakistan during the period of $1^{\text {st }}$ January 2011 to $31^{\text {st }}$ December 2013. Diagnosis was established by compatible history and ultrasonographic demonstration of posterior chamber mass with calcification. CT-Scan aided in diagnosis and also excluded extra scleral/intracranial extension. Examination under anesthesia allowed classifying the tumor according to Reese-Ellsworth classification system. Children of consenting parents were started on primary chemotherapy. Secondary treatment consisted of cryotherapy and/or argon laser photocoagulation.

RESULTS: The mean age of the cohort was 2.35 years. A total of $72 \%$ had advance stage IV or $\mathrm{V}$ disease. Secondary treatment was given in $43 \%$ eyes, whereas, $57 \%$ needed to be enucleated. Chemoreduction salvaged $43 \%$ of eyes. The mean survival in the cohort was 67.88 weeks and the Kaplan Meier cumulative 2 year survival rate is $77 \%$. Primary chemotherapy improved survival in the cohort (none died). The test statistic (log rank is 20.04 (df-I); $\mathrm{p}<0.00 \mathrm{I})$. But, was not attributed to preventing globe loss $\left(\mathrm{x}^{2}=2.52(\mathrm{df}-\mathrm{I})\right.$, $p=0.1 \mid$ 2). Preventing globe loss was attributed to the stage of the disease at time of diagnosis $\left(\mathrm{x}^{2}=11.476(\mathrm{df}-\mathrm{I}), \mathrm{p}<0.00 \mathrm{I}\right)$.

CONCLUSION: Primary chemotherapy improves survival but not globe salvage in children with retinoblastoma. Invariably, the deciding variable for vision and globe salvage is the stage of disease at diagnosis.

KEY WORDS: Retinal Neoplasms (MeSH); Eye Neoplasms (MeSH); Retinoblastoma (MeSH); Chemotherapy (MeSH); Cryotherapy (MeSH).

THIS ARTICLE MAY BE CITED AS: Saeed TM, Iqbal Z. Outcome of children with retinoblastoma treated with primary chemotherapy. Khyber Med Univ J 2019; I I ( ): I2-6. DOI: 10.35845/kmuj.2019. I82 I6.

\section{INTRODUCTION}

$R^{\mathrm{e}}$ etinoblastoma is the most common primary intraocular malignancy of the developing retina in children' representing approximately $4 \%$ of childhood $^{2}$ and less than $1 \%$ of all human cancers. ${ }^{2}$ It may affect either eye and has no gender, racial or geographical predilections. ${ }^{3}$

Retinoblastoma is $60-70 \%$ unilateral and most are non-hereditary (median age at diagnosis is 2 years). Retinoblastoma is bilateral in $30-40 \%$ of cases (median age at diagnosis is I year). ${ }^{4}$ This represents mainly hereditary retinoblastoma. The frequency varies from country to country and is between I in I5000 to I in 20000 live births. ${ }^{5}$ Approximately, 260 cases are newly diagnosed each year in Pakistan, and worldwide estimates are upto 8000 yearly. ${ }^{6}$
I Ophthalmology Ward, Saidu Teaching Hospital, Saidu Sharif, Swat, Pakistan Email: tarik_saeed@yahoo.com Contact \#: +92-3329293129

$2 \bowtie$ Department of Ophthalmology, Medical Teaching Institute Lady Reading Hospital, Peshawar, Pakistan.

Email:dr_ziqbal@yahoo.com

Contact \#: +92-3339131288, +92-3009595976

Date Submitted: February 02, 2018

Date Last Revised: March 18, 2019

Date Accepted: $\quad$ March 19, 2019

Leukocoria is the most frequent sign $(60 \%)$ and is associated with retinoblastoma in almost half of all infants presenting with a white pupil.? Calcium complexed with denatured DNA is a histological hallmark, which can be easily detected by an ophthalmic ultrasound in the outpatient department. Examination under anesthesia allows visual confirmation of diagnosis and helps in charting treatment. $^{8}$

The treatment of retinoblastoma has evolved over the years. Previously enucleation was done to save the life of the child. Now treatment concentrates on not only life but also salvaging the globe and vision of the child. Primary chemotherapy has been increasingly used in the treatment of intraocular retinoblastoma. 'It has provided an opportunity for tumor shrinkage (chemoreduction) $^{10}$ and thus, a chance to use adjuvant treatment modalities such as cryotherapy and argon photocoagulation. ${ }^{10-12}$ This has resulted in better survival with vision and globe salvage.

The study was performed to assess the response to primary chemotherapy and its effect on survival for children with retinoblastoma. Also the study aimed to ascertain variables contributing to globe salvage.

\section{METHODS}

This was a hospital-based cohort prospective study of 91 children with retinoblastoma out of which 27 children (32 eyes) fulfilled the inclusion criteria. These children were admitted to Ophthalmology Unit, Lady Reading Hospital, Peshawar, Pakistan during the period of $\mathrm{I}^{\text {st }}$ January $20 \mathrm{II}$ to $3 \mathrm{I}^{\text {st }}$ 
TABLE I: TREATMENT OUTCOME FOR PRIMARY CHEMOTHERAPY IN COMPARISION TO OTHER TREATMENT

\begin{tabular}{|l|l|c|c|c|c|c|}
\hline \multicolumn{2}{|c|}{ Outcome } & Chemotherapy & Others & $\mathbf{X}^{2}$ & df & p-value \\
\hline \multirow{2}{*}{ Globe Lost } & Count & 13 & 3 & & & \\
\cline { 2 - 5 } & Expected & 14.3 & 1.7 & \multirow{3}{*}{2.250} & I & \multirow{2}{*}{0.112} \\
\hline \multirow{2}{*}{ Globe Salvage } & Count & 12 & 0 & & & \\
\cline { 2 - 5 } & Expected & 10.7 & 1.3 & & & \\
\hline
\end{tabular}

TABLE II: EFFECT OF NUMBER OF CHEMOTHERAPY CYCLES ON GLOBE SALVAGE

\begin{tabular}{|l|l|c|c|c|c|c|}
\hline \multicolumn{2}{|c|}{ Outcome } & $\begin{array}{c}\text { Chemotherapy } \\
(<6 \text { cycles })\end{array}$ & $\begin{array}{c}\text { Chemotherapy } \\
(>6 \text { cycles })\end{array}$ & $X^{2}$ & df & p-value \\
\hline \multirow{2}{*}{ Globe Lost } & Count & 6 & 10 & & & \\
\cline { 2 - 5 } & Expected & 5.1 & 10.9 & \multirow{3}{*}{0.491} & I & \multirow{2}{*}{0.483} \\
\hline \multirow{2}{*}{ Globe Salvage } & Count & 3 & 9 & & & \\
\cline { 2 - 5 } & Expected & 3.9 & 8.1 & & \\
\hline
\end{tabular}

TABLE III: EFFECT OF STAGE OF DISEASE ON GLOBE SALVAGE

\begin{tabular}{|l|c|c|c|c|c|}
\hline \multicolumn{1}{|c|}{ Outcome } & Less Advance & Advance Stage & $\mathbf{X}^{2}$ & df & p-value \\
\hline Globe Lost & $\mathrm{I}$ & $\mathrm{I}$ & \multirow{2}{*}{$\mathrm{II} .476$} & $\mathrm{I}$ & $<0.00 \mathrm{I}$ \\
\hline Globe Salvage & 8 & 4 & & & \\
\hline
\end{tabular}

December 2013. After establishing a diagnosis, each child was examined under anesthesia to assess the full spectrum of disease. The number and size of tumors, their location inside the eye and any associated seeding were recorded for each tumor. These eyes with retinoblastoma were classified according to Reese-Ellsworth classification system. ${ }^{9}$ The parents were informed about the findings, treatment protocols were discussed and written consent obtained. Children of parents consenting to the treatment regimen were included in the study. Children with overt extraocular disease were excluded from the study.

A treatment plan was tailored for each child consisting of chemotherapy primarily $^{13-14}$ in liaison with an oncologist. An intravenous cocktail of Vincristine $1.5 \mathrm{mg} / \mathrm{m}^{2}$, Carboplantin $560 \mathrm{mg} / \mathrm{m}^{2}$ and Etoposide $150 \mathrm{mg} / \mathrm{m}^{2}$ was given on DAY 0 and Etoposide $150 \mathrm{mg} / \mathrm{m}^{2}$ on DAY I. Secondary treatment was decided according to response to chemotherapy. Each child was reviewed after $2^{\text {nd }}$, before $5^{\text {th }}$ and after $6^{\text {th }}$ cycles of chemotherapy, which were given 3-4 weeks apart. ${ }^{15}$ Secondary treatment consisted of cryotherapy, argon laser photocoagulation, enucleation, exenteration, and palliative therapy. ${ }^{11-13}$
Argon photocoagulation was performed under general anesthesia for posteriorly located tumors using an indirect ophthalmoscope mounted on an argon laser (Quantel Medical Argon laser with Keelar indirect ophthalmoscope). Using a 20 diopter lens, the entire surface and surroundings of the tumor were coagulated with a laser intensity increased from 300 milliwatt and $\mathbf{0 . 2}$ second duration till the achievement of a clearly visible white mark. These laser marks were overlapped to cover the tumor. Cryotherapy using a triplefreeze-thaw method via transconjunctival route was done for anteriorly located tumors and also for posterior tumors through a conjunctival peritomy. Cryotherapy was performed before the $5^{\text {th }}$ cycle after chemoreduction was achieved. Additional cryotherapy was performed after the $6^{\text {th }}$ and subsequently whenever typical regression pattern was not observed or there was evidence of regrowth at specified followup schedules. Each focal therapy was followed by two additional chemotherapy cycles and a review. A maximum of 12 cycles of chemotherapy were set as the upper limit. Enucleation was performed when tumor was found to be chemo-resistant after a minimum of two cycles of chemotherapy. Treatment failure was defined as chemo-resistance (progression in size) after a minimum of two cycles of chemotherapy, initial response and then relapse and the development of vitreous, subretinal or anterior chamber seeds.

Epidemiology and end results were statistically analyzed using SPSS version 10. The cumulative survival rate was calculated by the Kaplan-Meier method. Chi square analysis of outcome variables e.g. primary chemotherapy, staging of tumors and end outcome of treatment was done.

\section{RESULTS}

The cohort consisted of 27 children, 22 unilateral and 5 bilaterally affected ( 32 eyes) with a mean age of 2.35 years. Majority of the children presented with advance stage IV and $\mathrm{V}$ disease i.e. $72 \%$ ( 23 of 32 eyes).

Chemotherapy was offered to each child as a primary treatment of which 24 consented to the treatment protocol. Two children opted for primary exenteration and I for primary enucleation, all unilaterally affected. These three children neither received any chemotherapy before or after the primary treatment due to noncompliance of parents with treatment protocol. All three children eventually died, with a mean survival of 29.67 weeks. One child unilaterally affected received 4 cycles of chemotherapy, was lost to follow-up and dropped out of the study.

The cohort for secondary treatment thus consisted of 23 children ( 28 eyes). Secondary treatment consisted of chemotherapy plus adjuvant focal therapy (cryotherapy \&/or argon photocoagulation) in 12 (43\%) eyes and enucleation in 16 (57\%) eyes. Invariably, those eyes in which tumors responded to chemoreduction were salvaged (43\%).

The mean survival in the cohort was 67.88 weeks and the Kaplan Meier cumulative 2 year survival rate is $77 \%$ (Figure I).

Primary chemotherapy improved survival with a test statistic of $20.4(\mathrm{df}=$ 
I; $\mathrm{p}<0.00 \mathrm{I}$ ) (Figure 2). The corelational scatter-gram showed a linear relationship between number of chemotherapy cycles and treatment outcome with a correlational coefficient $R=0.434\left(r^{2}=0.189\right)$. Out of the 28 eyes on primary chemotherapy, 16 eyes (57\%) were lost and I 2 (43\%) salvaged. The test statistic accepted the null hypothesis $\left(x^{2}=2.52(d f=I ; p=0.112)\right.$ in that primary chemotherapy did not contribute statistically to globe salvage (Table I).

Nine out of 28 eyes received $<6$ cycles of chemotherapy during treatment. Six out of these 9 eyes were lost $(66.7 \%)$. Nineteen of 28 eyes received $>6$ cycles out of which 10 were lost $(52.6 \%)$ Although, chemotherapy improved survival in the cohort, the number of chemotherapy cycles has no effect on outcome for the globe $\left(x^{2}=0.491(d f=I\right.$; $\mathrm{p}=0.483)$ (Table II).

A total of 9 eyes were classified as less advance stage I, II and III disease and I 9 eyes as advanced stage IV and $V$ disease. In the less advance group $88.9 \%$ of the globes were salvaged and $11.1 \%$ lost, whereas, in the advance group $21.1 \%$ globes were salvaged and $78.9 \%$ lost. The test statistic gave a value of $x^{2}=$ II.476 $(\mathrm{df}=\mathrm{I}) ; \mathrm{p}=<0.00 \mathrm{I}$. The variable which contributed to preventing globe loss was the stage of the disease at the time of diagnosis (Table III).

\section{DISCUSSION}

In a previous study ${ }^{16}$ in the same unit, eyes with advance disease (stage IV and V) with no prospect of useful vision were not eligible for conservative treatment. Consequently, $94 \%$ of unilateral and $27 \%$ of bilaterally affected eyes were enucleated. In $20 \mathrm{II}$, following the changing trends in the treatment strategy for retinoblastoma, every child admitted to Ophthalmology Unit, Lady Reading Hospital, Peshawar, Pakistan was started on primary chemotherapy. The rationale was to defer enucleation so as to assess tumor response to chemoreduction which would offer a cure in some cases. In cases where a cure was not achieved, chemoreduction would at least allow sufficient time for parents to settle with the idea of their child losing an eye. Children refusing primary chemotherapy and those with overt extrascleral disease were managed surgically. With time, tumors with different stages of regression were seen. Some tumors regressed completely, whereas, others reduced to a size where complimentary cryotherapy and /or argon photocoagulation could afford globe salvage.

Out of 27 children (32 eyes) in the cohort, 24 children were started on primary chemotherapy all of whom survived the study. Two children opted for primary exenteration and one primary enucleation. None of these children received chemotherapy either before or after the primary treatment because of non-compliance of the parents with the treatment regimen. All three eventually died, with a mean survival of 29.67 weeks. Primary chemotherapy improved survival with a test statistic of 20.4 (df-I), p $<0.00 \mathrm{I}$. Generally, the more chemotherapy a child received better was the survival. $A$ weak positive correlation was established with an R value of $0.434\left(r^{2}=\right.$ 0.189). A similar improved survival was reported by Waddell KM. ${ }^{17} \mathrm{He}$ reports $37 \%$ lower risk of dying in 181 treated prior to and 89 after the introduction of chemotherapy into their treatment protocol in $2009 .^{17}$

Primary chemotherapy was well tolerable and improved survival without complications but was contributing to globe salvage. A total of 29 of 32 eyes received primary chemotherapy. One child, unilaterally affected, was lost to follow-up after receiving 4 cycles of chemotherapy. The cohort now consisted of 28 eyes of which 16 eyes were lost $(57 \%)$. Only 12 of 28 eyes (43\%), globes were salvaged. Primary chemotherapy did not contribute statistically to globe salvage, $\left(x^{2}=2.52\right.$ $(d f-I), p=0 . I I 2)$. In the absence of chemotherapy, the remaining 12 globes would have been lost. A better statement would be that chemotherapy salvaged those eyes in which tumors were chemo-sensitive and detected early. Studies have shown that chemotherapy alone has resulted in tumor control rates for Reese-
Ellsworth (R-E) group I-IV of $5 \mathrm{I}-86 \%$ and $25-38 \%$ in advanced tumors (R-E group V). ${ }^{18-19}$ When combined with focal laser consolidation the control rates increase to $62-100 \%$ and $47-83 \%$ respectively. ${ }^{20-21}$ Similarly, Bechrakis NE, et al. ${ }^{22}$ observes that primary chemotherapy is not equally effective in all children and advocates careful observation and consolidation with ancillary treatment.

In this study, we attempted to determine the effect of different treatment variables for globe salvage. One such variable was the number of chemotherapy cycles up to enucleation. Nine out of twenty eight eyes received $<6$ cycles of chemotherapy during the treatment regimen. Six of these eyes $(66.7 \%)$ were lost. Nineteen of twenty eight eyes received $>6$ cycles. Ten of the eyes in this group were lost $(52.6 \%)$. About half of the eyes (16/28) did not respond to chemotherapy regardless of the number of cycles given, $\left(x^{2}=0.491\right.$ (df- $\left.\left.I\right), p=0.483\right)$. Eventually, these unresponsive tumors will regrow or seed. Thus, a cutoff point should be established beyond which keeping the child on chemotherapy is no longer justifiable or curative. Similar recommendation is given by Zhao J, et al. ${ }^{23}$ who concluded that preenucleation chemotherapy in advanced Group E eyes increased the risk of metastatic death. We recommend a trial of chemotherapy to establish sensitivity of the tumor to chemotherapy. Chemo-resistant tumors and tumors extending extraocularly are enucleated after 2-3 cycles. Children with chemosensitive tumors are followed meticulously up to the age of 7 years. A high index of suspicion is maintained for tumor regrowth and new tumor formation. In such cases, two further cycles of chemotherapy and adjuvant therapy should be instituted. A maximum limit of 12 cycles of chemotherapy is advised.

Our study showed that primary chemotherapy and number of chemotherapy cycles did not affect the outcome for the globe. Another variable that was studied was the stage of disease at presentation. Only a small portion of the cohort, 9 of 28 eyes (32\%) presented with less advance 
Survival Function

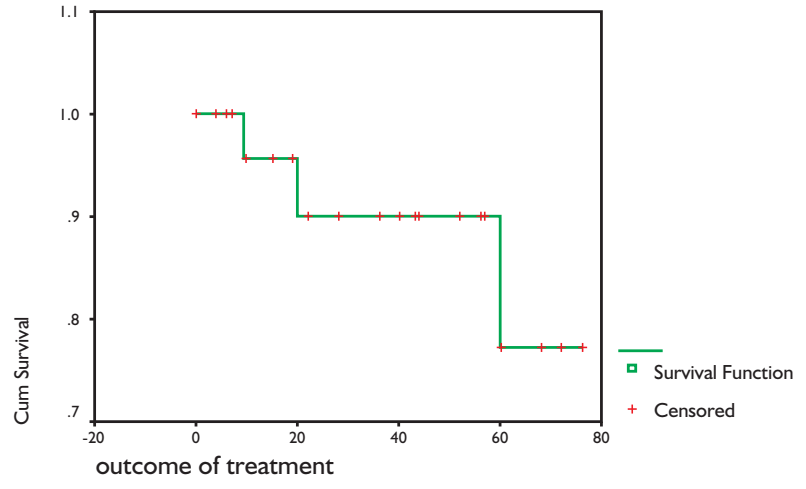

Figure I: Kaplan Meier cumulative two year survival rate

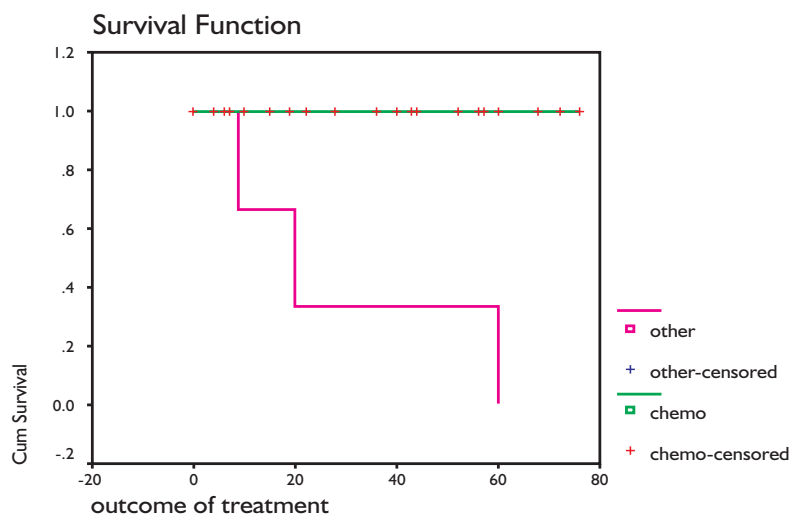

Figure 2: Survival rate on primary chemotherapy in comparison to other treatment disease. Only one globe was lost giving a salvage rate of $89 \%$. Advance disease was present in 19 of 28 eyes (68\%) of which 15 globes were lost. The globe salvage was $21 \%$. Globe salvage depends on the stage of disease at presentation, $\left(\mathrm{x}^{2}=\mathrm{I}\right.$ I.476 $(\mathrm{df}-\mathrm{I}), \mathrm{p}<$ $0.001)$. Late presentation not only endangers life but the child is also more likely to lose the globe. Similar results are reported by $\mathrm{Kim} \mathrm{JH}$, et al. ${ }^{18}$ who reported $86 \%$ globe salvage in low stage and $38 \%$ in high stage retinoblastoma. Shield $\mathrm{CL}$, et al. ${ }^{24}$ reports, I5\% enucleation of RE I to IV and $53 \%$ in group $V$ at 5 years.

In summary, for children in developing countries, the dilemma continues. Retinoblastoma can be treated effectively if detected early and thus awareness for both parents and doctors at the primary care level is crucial. Red reflex testing of children less than 5 years should be stressed upon in all forums concerned with child health. Appropriate counseling and meticulous followup are keys for successful treatment outcomes.

\section{CONCLUSION}

Primary chemotherapy improves survival but not globe salvage in children with retinoblastoma. Invariably, the deciding variable for vision and globe salvage is the stage of disease at diagnosis.

\section{REFERENCES}

I. Memon F, Rathi SL, Memon MH.
Pattern of solid pediatric malignant neoplasm at LUMHS, Jamshoro, Pakistan. J Ayub Med Coll Abbottabad 2007; 19(4):55-7.

2. Abrahamson DH. Retinoblastoma in the 20th Century: Past success and future challenges. The Weisenfeld lecture. Investigative Ophthalmol \& Visual Sci 2005 Aug;46(8):2684-9I. DOI: 10.1 167/iovs.04-| 462.

3. Bonanomi MTBC, de-Almeida MTA, Cristofani LM, Filho OV. Retinoblastoma: a three-year-study at a Brazilian medical school hospital. Clinics 2009;64(5):427-34. DOI: I0.1590/S I 807-59322009000 500010 .

4. Broaddus E, Tophan A, Singh AD. Incidence of retinoblastoma in the United States: 1975-2004. Br J Ophthalmol 2009 Jan;93(I):2I-3. DOI: I0.I I36/bjo.2008.138750.

5. Murphree AL, Samuel MA, Harbour JW, Mansfield NC. Retinoblastoma in Ryan SJ. St. Louis: 3rd ed. Retina mosby-Year Book, Inc; 2006:568.

6. Usmanov RH, Kivelä T. Predicted Trends in the Incidence of Retinoblastoma in the Asia-Pacific Region. Asia Pac J Ophthalmol (Phila) 2014 May-Jun;3(3):I5I-7. DOI: 10.1097/ APO. 00000000000 00060

7. Balmer A, Munier F. Differential diagnosis of leukocoria and strabismus, first presenting signs of retinoblastoma. Clinical Ophthalmol 2007 Dec; I (4):43 I-9.
8. Arif M, Kundi NK. Ultrasonography in diagnosis of retinoblastoma. Pak J Med Res 2010;49(1): 18-2.

9. Gombos DS, Kelly A, Coen PG, Kingston JE, Hungerford JL. Retinoblastoma treated with primary chemotherapy alone: the significance of tumour size, location, and age. $\mathrm{Br} J$ Ophthalmol 2002;86:80-3. DOI: 10.1/36/bjo. 86.1 .80 .

10. Shields CL, Meadows AT, Leahy AM, Shields JA. Continuing challenges in the management of retinoblastoma with chemotherapy. Retina 2004;24(6):849-62. DOI:10.10 97/ 00006982-2004 I 2000-0000।

I I. Gallie BL, Budning A, DeBoer G, Thiessen JJ, Koren G, Verjee Z, et al. Chemotherapy with focal therapy can cure intraocular retinoblastoma without radiotherapy. Arch Ophthalmol 1996;||4(II):|321-8. DOI: 10.1001/archopht.1996.01 I0 0140521001 .

12. Shields CL, Shields JA, Needle M, de Potter P, Kheteral S, Hamada A, et al. Combined chemoreduction and adjuvant treatment for intraocular retinoblastoma. Ophthalmology 1997; I04(I2):2 I0I-II. DOI: I0.10 I6/S0I6I-6420(97)30053-0.

13. Murphree AL, Villablanca JG, Deegan WF 3rd, Sato JK, Malogolowkin $M$, Fisher $A$, et al. Chemotherapy plus local treatment in the management of intraocular retinoblastoma. Arch Ophthalmol 
1996; I I4(II):1348-56. DOI:10 . 1001/archopht. 1996. 0110014054 8005.

14. Zafar SN, Siddiqui SN, Zaheer N. Tumor regression patterns in retinoblastoma. J Coll Physicians Surg Pak 20 I6;26(I I):896-9.

15. Kingston JE, Hungerford JL, Madreperla SA, Plouman PN. Results of combined chemotherapy and radiotherapy for advanced intraocular retinoblastoma. Arch Ophthalmol 1996; II4(II):I33943. DOI: $10.1001 /$ archopht. 1996. 01100140539004 .

16. Iqbal Z, Saeed TM. Frequency of retinoblastoma at Lady Reading Hospital, Peshawar, Pakistan. Asian J Ophthalmol 20 I I; 2(3): I40-3.

17. Waddell KM, Kagame K, Ndamira A, Twinamasiko A, Picton SV, Simmons IG, et al. Improving survival of retinoblastoma in Uganda. $\mathrm{Br}$ J Ophthalmol 2015;99(7):937-42. DOI: I0.I I36/bjophthalmol-20 I4306206.

18. Kim JH, Yu YS, Khwarg SI, Choi HS,
Shin HY, Ahn HS. Clinical result of prolonged primary chemotherapy in retinoblastoma patients. Korean J Ophthalmol 2003;17(1):35-43. DOI: I0.334I/kjo.2003.17.I.35.

19. Rodriguez-Galindo C, Wilson MW, Haik BG, Merchant TE, Billups CA, Shah N, et al. Treatment of intraocular retinoblastoma with vincristine and carboplatin. J Clin Oncol 2003;2I(I0):2019-25. DOI: 10.1200/JCO.2003.09.103.

20. Schefler AC, Cicciarelli N, Feuer W, Toledano S, Murray TG. Macular retinoblastoma: Evaluation of tumor control, local complications, and visual outcomes for eyes treated with chemotherapy and repetitive foveal laser ablation. Ophthalmology 2007; I I4(I): 162-9. DOI: 10.1016/j.ophtha.2006. 06.042 .

2I. Shields CL, Mashayekhi A, Au AK, Czyz C, Leathey A, Meadows At, et al. The International classification of retinoblastoma predicts chemoreduction success. Ophthalmology 2006; II3(II):
2276-80.DOI: I0.10 I6/j.ophtha. 2006. 06.018.

22. Bechrakis NE, Bornfeld N, Schueler A, Coupland SE, Henze G, Foerster $\mathrm{MH}$. Clinicopathologic features of retinoblastoma after primary chemoreduction. Arch Ophthalmol 1998; | | 6(7):887-93. DOI: I0. 100 I /archopht. I 16.7.887.

23. Zhao J, Dimaras H, Massey C, XuX, Huang D, Li B, Chan HS, et al. Preenucleation chemotherapy for eyes severely affected by retinoblastoma masks risk of tumor extension and increases death from metastasis. Clin Oncol 200I;29(7):845-5I. DOI: $10.1200 / J C O .2010 .32 .5332$.

24. Shields CL, Honavar SG, Meadows ST, Shields JA, Demirci H, Singh A, et al. Chemoreduction plus focal therapy for retinoblastoma: Factors predictive of need for treatment with external bean radiotherapy or enucleation. Am J Ophthalmol 2002; 133(5):657-64. DOI: 10.1016/ S0002-9394(02)0I348-X.

\section{AUTHORS' CONTRIBUTIONS}

Following authors have made substantial contributions to the manuscript as under:

TMS \& ZI: Concept and study design, acquisition, analysis \& interpretation of data, drafting the manuscript, critical review, final approval of the version to be published.

Authors agree to be accountable for all aspects of the work in ensuring that questions related to the accuracy or integrity of any part of the work are appropriately investigated and resolved.

\begin{tabular}{|c|}
\hline CONFLICT OF INTEREST \\
Authors declared no conflict of interest \\
GRANT SUPPORT AND FINANCIAL DISCLOSURE \\
NIL
\end{tabular}

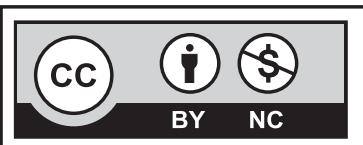

This is an Open Access article distributed under the terms of the Creative Commons Attribution-Non Commercial 2.0 Generic License.

KMUJ web address: www.kmuj.kmu.edu.pk

Email address: kmuj@kmu.edu.pk

KMUJ 2019, Vol. I I No. I 